\title{
Interrelationships of quantitative asthma-related phenotypes in the Epidemiological Study on the Genetics and Environment of Asthma, Bronchial Hyperresponsiveness, and Atopy
}

Oryszczyn Marie-Pierre ${ }^{1 *}$, Bouzigon Emmanuelle ${ }^{2}$, Maccario Jean ${ }^{13}$, Siroux Valérie ${ }^{4}$, Nadif Rachel ${ }^{1}$, Wright Anne ${ }^{5}$, Kauffmann Francine ${ }^{1}$

1 Recherche en épidémiologie et biostatistique INSERM : U780, INSERM : IFR69, Université Paris Sud - Paris XI, 16, Avenue Paul Vaillant-Couturier 94807 VILLEJUIF CEDEX,FR

${ }^{2}$ Méthodologie statistique et épidémiologie génétique de maladies multifactorielles INSERM : U794, Université d'Evry-Val d'Essonne, Tour Evry 2 - 2 ème étage 523 Place des Terrasses de l'Agora 91034 Evry,FR

${ }^{3}$ Université René Descartes Université Paris Descartes - Paris V, FR

${ }^{4}$ Groupe de Recherche Sur Le Cancer du Poumon : Bases Moléculaires de la Progression Tumorale, Dépistage et Thérapie Génique INSERM : U578, Institut Albert Bonniot, Rond Point de La Chantourne 38706 LA TRONCHE CEDEX,FR

5 ARC, Arizona Respiratory Center University of Arizona College of Medicine, 1501 N. Campbell Ave.,Suite 2349. PO Box 245030 Tucson, AZ 85724-5030,US

* Correspondence should be adressed to: Marie-Pierre Oryszczyn <marie-pierre.picot@inserm.fr>

\section{Abstract \\ Background}

Delineating asthma subphenotypes is of interest to understand its etiology. Few studies have addressed the interrelationships of quantitative asthma-related traits.

Objective

To study the interrelationships of allergy markers and $\mathrm{FEV}_{1}$ in relation to asthma and gender in children and adults.

Methods

Total IgE, skin prick test positivity (SPT+), eosinophil counts and $\mathrm{FEV}_{1}$ were assessed in 299 asthmatic cases (children and adults) recruited in chest clinics and 309 non asthmatic population-based controls in the French Epidemiological study on the Genetics and Environment of Asthma, bronchial hyperresponsiveness and atopy (EGEA).

Results

Allergy parameters were significantly higher in asthmatic cases than in controls for children and adults and for both genders. Gender and age modified the pattern of concordance of high IgE, SPT + and eosinophilia among asthmatics, with the greatest overlap in male children $(64 \%)$ and the lowest in female adults $(24 \%)$. Patterns of change over the lifespan of IgE, eosinophil count and $\mathrm{FEV}_{1} / \mathrm{H}^{2}$ varied, with the acceleration of $\mathrm{FEV}_{1}$ decrease being particularly evident in asthmatic adults. In adult cases and controls, SPT+ (particularly to indoor allergens) was significantly related to IgE, but not to eosinophils. The association of eosinophils with IgE was evident only in children. Environmental factors (smoking, pets, country living) did not alter the patterns observed.

Conclusions

Each allergy-related phenotype showed a distinct relation with asthma, with the role for eosinophils being different than IgE and SPT.

Clinical implication

Taking age and gender into account is essential for understanding the interrelationships of the various allergy-related phenotypes to asthma status.

MESH Keywords Adult ; Age Factors ; Allergens ; immunology ; Asthma ; epidemiology ; genetics ; immunology ; physiopathology ; Bronchial Hyperreactivity ; Child ; Environment ; Eosinophils ; immunology ; Female ; Forced Expiratory Volume ; Genetic Predisposition to Disease ; Humans ; Hypersensitivity, Immediate ; Immunoglobulin E ; blood ; Male ; Phenotype ; Sex Factors ; Skin Tests

Author Keywords allergy ; asthma ; eosinophils ; epidemiology ; gender ; IgE ; lung function

\section{INTRODUCTION}


The current debate regarding eosinophils no longer considers whether they are friend or foe 1, but rather focuses on determining the circumstances in which they act as a foe2,3. Eosinophils were among the first allergy markers studied as potential risk factors for FEV decline in the context of the Dutch hypothesis4, which postulates that features of asthma are risk factors of COPD. Although investigations of skin prick test response and $\mathrm{IgE}$ support the hypothesis, the relation of various allergy traits to $\mathrm{FEV}_{1}$ decline varied between studies, suggesting disease heterogeneity5-7. Skin test positivity, high serum total IgE level and peripheral blood eosinophilia likely represent different expressions of the atopic phenotype8,9, which may explain their varied relation with $\mathrm{FEV}_{1}$. Eosinophils and other allergy markers are strongly related to asthma, but not all asthmatics present with allergic traits, and the attributable risk of allergy in asthma has been questionned10. Furthermore, the interpretation of the role of eosinophils is more nuanced after studies in adults have shown no effect of anti IL-5 treatment, an eosinophil-specific cytokine2, on airways dysfunction in asthma.

Each marker of allergy shows a different relation with age, with eosinophils decreasing early in infancy, whereas IgE increases to early adulthood. Sex-related patterns have also been shown, with higher values of all parameters in males than in females, but stronger associations of eosinophils with asthma in women with persistent asthma11. Different patterns of familial correlation of asthma-related phenotypes have been observed according to the mode of ascertainment of the families (offspring or parents) 12. In addition, environmental 13-15 determinants of eosinophils, IgE and skin tests have been identified.

Few epidemiological studies have collected data on the various markers simultaneously in subjects over the life span and no study has assessed their interrelationships at the phenotypic level in relation to age, gender and asthma status. The aim of the present study is to assess the relationships between total IgE, skin prick test response, eosinophils and $\mathrm{FEV}_{1}$ in children and adult asthmatic cases and controls from the EGEA study taking into account asthma and gender. Specific consideration is given to eosinophils and to quantitative assessment of skin prick test response, recently validated 16 .

\section{METHODS}

\section{Population}

EGEA is a case-control and family study of adult and childhood asthma, cases were recruited in chest clinics as well as population-based controls. The protocol has been described elsewhere17,18. All subjects have been extensively characterised regarding phenotypic and environmental characteristics by standardised questionnaires $13,15,17,18$. The present analysis concerns 299 asthmatic cases and 309 non asthmatic controls with data on IgE, skin prick tests, eosinophils and $\mathrm{FEV}_{1}$. The proportion of missing data (13.8\%) was similar in cases and controls and by gender. Adult cases with missing data were older than other subjects (43.3 vs. 37.8 ; $p=0.03)$. The study was approved by the appropriate Institute Review board and informed consent was obtained from all subjects (parents for the children) (See additional Methods information in the Online Repository).

\section{Allergy markers, lung function and asthma severity}

Total IgE (IU/ML) was measured by radioimmunoassay 13. Specific IgE to a mixture of several inhalant allergens were assessed using the Phadiatop ${ }^{\circledR}$ (Pharmacia diagnostics, AB, France). The exact composition of the aero allergens present in the Phadiatop has not been reported by the manufacturer, but information on its constituents is available. The percentage binding of the Phadiatop ${ }^{\circledR}$ was classified as positive or negative according to the reference serum value. Skin prick tests (SPT) were performed to 11 allergens (including moulds, indoor and outdoor allergens) A quantitative score (SPTQ) was constructed as being the number of positive tests results and validated regarding its biometric properties 16 . Total and differential white blood cell counts were obtained by standard methods, apparatus used were those available in each center.

The maximum $\mathrm{FEV}_{1}$ of 3 maneuvers was used to calculate the $\mathrm{FEV}_{1} \%$ predicted correcting for height, age and gender.

To assess asthma severity, a score (1-4) was calculated as previously described19.

\section{Environmental factors}

Smoking13, contact with pets20 and country living15 (an indirect marker of contact with livestock), previously shown in the EGEA study to relate to total $\mathrm{IgE}$, SPT+ (any wheal $\geq 3 \mathrm{~mm}$ ), eosinophils or $\mathrm{FEV}_{1}$ were considered in the adult analyses. Active smoking (non smokers, ex-smokers and smokers), childhood exposure to cat ( $\leq 16$ years of age) and ever living in the country were included in models to assess whether the pattern observed between quantitative trait phenotypes were explained by environmental factors.

\section{Statistical methods}

Dichotomous variables used in analyses were SPT + , eosinophilia $(>5 \%)$, Phadiatop ${ }^{\circledR}+$, and high $\operatorname{IgE}(\geq 100 \mathrm{IU} / \mathrm{ml})$. IgE and eosinophils were log transformed and expressed in geometric means (GM). Analyses regarding eosinophils also used tertiles computed separately for adults and children. Standard statistical tests (linear and logistic regression) were used to assess the interrelations between asthma-associated traits in models including age, sex and environmental factors. Analyses on the relationships of eosinophils with FEV1 
were adjusted on age, sex, smoking and inhaled steroid treatment, and on age, sex, and smoking for other allergy parameters. SAS software was used (version 9.12003 Cary, NC, USA). (See additional Methods information in the Online repository).

\section{RESULTS}

Total IgE, Phadiatop ${ }^{\circledR}$ positivity, SPT and eosinophil counts, considered either dichotomously or quantitatively, were significantly higher for cases vs. controls among both children and adults of both genders (Table I). Both SPT+ and high IgE was evident in about $90 \%$ of the child cases. The greatest difference between cases and controls in SPT was observed for indoor allergens, in particular for DerP, for which $75.6 \%$ vs. $21.2 \%$ in pediatric cases and controls, and $46.2 \%$ vs. $15.3 \%$ in adult cases and controls, were positive. For outdoor allergens, timothy grass positivity was the most common (38.2\% vs. $18.2 \%$ in children and $27.3 \%$ vs. $16.1 \%$ in adults respectively). $\mathrm{FEV}_{1}$ was significantly lower in cases than in controls, especially in adults.

Among cases, nearly all were in active phase. More precisely, $111(90.2 \%)$ children and 163 (92.6\%) adults reported attacks in the last 12 months and among those without attacks in that period, 5 children and 12 adults were using inhaled steroids. Among paediatric cases 23 $\%, 33 \%, 17 \%, 27 \%$ were in each asthma severity category from mild to severe, with comparable proportions being $7 \%, 30 \%, 21 \%$ and 42 $\%$ in adults.

\section{Gender and age}

Among asthmatics, there was a greater overlap of the three allergy markers among children than among adults for both genders (Fig 1 ). A substantial proportion (18.4\%) of women with asthma had no marker of allergy, whereas $2.3 \%$ of male asthmatics lacked any marker of allergy $(\mathrm{p}=0.001)$. Stratifying the sample according to smoking, country living or pet exposure did not change the pattern.

The pattern of change with age of all quantitative parameters was studied cross-sectionally by asthma status. FEV ${ }_{1} /$ height 2 was used to adjust for the dimensional aspect of growth. Quadratic models gave the best fit for eosinophils and lung function with age, capturing the marked decrease of eosinophils during childhood, and the pattern of lung growth during childhood followed by decline in lung function in adulthood (Fig 2). The best fit for log IgE was a linear decrease over the age range studied. For SPTQ, a non significant decrease was observed after 35 years of age, in both cases and controls. For all parameters, curves for allergic markers were higher but roughly parallel along the life span between cases and controls. For $\mathrm{FEV}_{1} / \mathrm{H}^{2}$, the curve of cases started below that of controls, remained parallel till mid adulthood and then showed an acceleration of decline with age (Fig 2). A similar pattern was observed when considering FEV $_{1}$ expressed in liters or $\mathrm{FEV}_{1} \%$ predicted (according to external reference values) instead of $\mathrm{FEV}_{1} / \mathrm{H}^{2}$ (data not shown). Separate models for males and females were represented (See Figure E1 in the Online Repository).

Among asthmatics, analyses taking the age of onset into account showed that adults with an early age of onset $(<4$ years $)$ had higher SPTQ than those with an age of onset of 4 years or more, and were younger at the time of the study. SPTQ values were 1.96 vs. 1.57 ( $p=$ 0,002 ) in women and 2.67 vs. 2.03 (NS) in men respectively. The associations were similar after adjustment for age at assessment (or for age and smoking).

\section{Relationships between total IgE, specific IgE, skin prick tests}

Total IgE was significantly associated with SPT+ in adult and child controls (73 vs. 22 and $86 \mathrm{vs.} 31 \mathrm{IU} / \mathrm{ml}$ respectively) and in adult cases ( 248 vs. $96 \mathrm{IU} / \mathrm{ml}$ ); all p < 0.004. In asthmatic children, nearly all of whom were SPT+, the association of IgE to SPT+ and SPTQ did not reach statistical significance (see Table E1 in the Online Repository), even after adjustment for age and sex. Among child controls, the association between SPT and IgE was strongest for outdoor allergens and remained significant after adjustment for age and sex. Among adult cases and controls, the association between SPT and IgE was strongest for indoor allergens. Associations between total IgE and SPT + were not modified by adjustment for potential confounders (age, gender, smoking and country living (see Table E1 in the Online Repository).

The concordance of Phadiatop® with SPT+ was high, with overall kappa coefficients being 0.49 and 0.44 for cases and controls among children, and 0.68 and 0.54 for cases and controls among adults. Excluding Aspergillus and blatta from the definition of SPT+ led to a slight increase in the kappa statistic. Considering all subjects together, the positive and negative predictive values of Phadiatop $₫$ for any of the 11 allergens were $90 \%$ and $78 \%$.

\section{Relationships of $\mathrm{FEV}_{1}$ and asthma severity with IgE and skin prick tests}

In children, $\mathrm{FEV}_{1}$ was unrelated to IgE, SPT+ or SPTQ in cases and in controls. In adult cases, a significant positive association of $\mathrm{FEV}_{1} \%$ with SPT+ was observed. However, non atopic adult cases were 10 years older than atopic cases (46.9 yrs vs. 34.4 yrs) and the association of SPT+ with $\mathrm{FEV}_{1}$ disappeared after adjustment for age (84.2\% vs. $89.0 \%$ ). No association was observed of $\mathrm{FEV}_{1}$ with SPTQ. Among asthmatics, associations of allergy markers with asthma severity score showed that there was no clear pattern of IgE in relation to asthma severity even after taking into account age, sex and smoking in the analyses (See Table E2 in the Online Repository).

Page 3/9 


\section{Relationships between eosinophil counts with other allergy markers, FEV $_{1}$ and asthma severity}

Because of the marked association of eosinophils to age, analyses of the relation with other allergy markers was conducted using age-specific (children and adults) eosinophil tertiles (Fig 3). In children, IgE increased significantly with eosinophil tertile both in cases and in controls. For SPTQ, the pattern was complex: eosinophils were significantly inversely related to SPTQ in cases, whereas a significant positive association among controls was observed. Child cases in the lowest eosinophil tertile were more often under inhaled steroids than in the other tertiles $(78.9 \%, 53.5 \%, 55.9 \%$ respectively). Eosinophils were unrelated to atopy, except among child controls for whom the prevalence of atopy increased by eosinophil tertile $(36.7 \%, 44.4 \%, 80.0 \%$ of SPT + for the first, second and third tertiles, respectively). For $\mathrm{FEV}_{1}$, there was a non-significant inverse relation with eosinophils for both cases and controls. In adults, there was no clear pattern. None of the associations of eosinophil tertiles with the other parameters were modified by taking environmental factors into account. Among asthmatics, no particular pattern was evidenced regarding the association of asthma severity score and eosinophils (See Table E2 in the Online Repository). Results were similar when inhaled steroid treatment was excluded from construction of the severity variable (data not shown).

\section{DISCUSSION}

The EGEA study, with its well-characterized asthmatics and population-based controls, provides an opportunity to assess the interrelationships of various quantitative asthma-related phenotypes. In this study conducted both in children and adults, the interrelationships of asthma-related quantitative phenotypes depend, not only on asthma, but also on age and gender. These variables modified the pattern of association between IgE, SPT + and eosinophilia among asthmatics, with the greatest overlap occurring in male children and the least in female adults. Eosinophils were significantly related to IgE and SPTQ in children only. Importantly, environmental factors, deleterious or protective, previously shown to relate to allergy markers did not explain the patterns observed.

We previously reported that eosinophilia was more strongly related to childhood-onset asthma among females11. Here we show that gender had a marked influence, not only on the level of allergy markers, but also on their interrelationships. Among asthmatics, significantly more women than men did not have high IgE, atopy and eosinophilia; this group has been little studied. Immunological

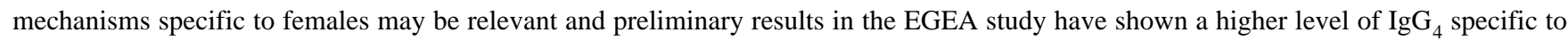
cat both in female cases and controls21. This finding suggests that sensitization, tolerance and other mechanisms may depend on sex, possibly being hormone-dependent. We previously showed that asthma severity increases with BMI in women with early menarche only 22 , but early menarche did not modify the present findings. These results add to the evidence that both the phenotypic presentation of asthma (here, allergy) and the risk factors for asthma differ for females and males23,24, in particular in adulthood.

At any age, prevalence of high IgE, SPT, SPTQ, and eosinophilia was greater for cases than controls, indicating that these markers represent asthma-related quantitative phenotypes. However, it cannot be inferred from these associations that these markers are indeed true intermediate phenotypes (i.e. on the causal pathway) as opposed to being associated traits 10 . Nevertheless, the strength of the association is a major argument to search genetic factors of these parameters along with those of asthma. Indeed, genetic studies have increasingly focused on the quantitative traits associated with asthma as relations with these more specific phenotypes are likely to help to disentangle the genetic determinants of this complex disease.

In our population, the increase of IgE from early childhood to adulthood was not evident as in Barbee et al 25, likely due to the small number of controls in this age range and the bias introduced by recruiting of asthmatic cases through chest clinics. Whereas SPT response, considered either dichotomously or quantitatively, was strongly related to IgE, eosinophils had markedly weaker associations with the other allergy parameters. Responsiveness at the skin level by using SPT and an index of polysensitization (SPTQ, Phadiatop ${ }^{\circledR}$ ), showed

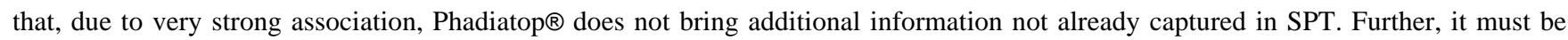
emphasized that positivity to this test is not specific for single sensitization. In children, IgE was most strongly associated with SPT response to outdoor allergens, whereas among adults, the indoor allergens showed the strongest relation with IgE. Interestingly, adults with an early age of onset had higher SPTQ, confirming that not only childhood onset but also early life onset is an interesting subphenotype of asthma to be considered in further studies. The lack of association of polysensitization with asthma severity in adults confirms previous observations from the EGEA study 26.

In children only, eosinophils were significantly related to IgE. While we observed the expected relationship between atopy and eosinophils among child controls, it was not the case in asthmatic children, as this relation appeared to be masked by medication use in the asthmatic children. The strength of the association of IgE with SPT was difficult to assess as nearly all asthmatic children were SPT+. These findings add to the epidemiologic evidence that eosinophilia in childhood, which has been little studied, may represent a different inflammatory state than it does in adulthood and may be etiologically linked to the development of asthma in childhood. This observation is of potential clinical importance, as studies questioning the efficacy of anti-IL5 treatment have been conducted in adults only, thus cannot be directly extrapolated from adults to children27. Clearly, more research is needed to understand the role of these cells in asthma2,8,2830. The lack of association of eosinophils with asthma severity observed here likely pertains to the observational nature of the population 
and recruitement of asthmatics in chest clinics, and thus does not conflict with the effect of inhaled steroids on eosinophils observed in clinical trials31. The difference in $\mathrm{FEV}_{1}$ between cases and controls, although apparent in childhood, was more noticeable in adulthood, which supports the speculation that remodelling-related events that are dependent on the duration of asthma32. In children, parameters other than lung function characterize asthma severity33,34, it would be of interest to assess whether the level of eosinophilia in asthmatic children predicts the persistence of severity of asthma into adulthood. Future epidemiological studies should be undertaken to determine genetic and environmental determinants of eosinophilic inflammation and its role in allergy and asthma in each gender over the life span.

A major limitation of our analysis is the cross-sectional nature of the data, but no longitudinal study could easily provide data from 7 to 70 years. As cohort effects likely modify the patterns, both cross-sectional and longitudinal studies are necessary to comprehensively approach life span patterns. A follow-up study currently in progress will help to assess whether factors related to low FEV 1 cross-sectionally, such as atopy, influence $\mathrm{FEV}_{1}$ decline over 10 years. A second limitation of our study was the difficulty of analyzing the pattern in controls, who appear more atopic than expected but who rarely present with eosinophilia. Although the recruitment of cases from chest clinics provided probands with a definitive diagnosis 17, it precludes the generalisation of the findings to asthma in general. Studies in larger populations would be useful to assess the relationships between the various markers in non asthmatics.

Environmental factors undoubtedly play a key role in the increase of asthma incidence in the last decades and substantial research is being directed to understanding the role of environmental factors on allergy-related phenotypes 13-15,21,35-37. However, environmental factors associated specifically to eosinophilia are not yet known. None of the environmental factors previously associated with allergy markers16,20 in the EGEA study (active and passive smoking, country living, early exposure to cat) modified, even slightly, the pattern of relationships between allergy markers or between allergy markers and $\mathrm{FEV}_{1}$. This is an important unexpected result, which suggests that genetic factors and more likely gene-environment interactions may play a major role in the phenotypic expression of asthma-related traits.

Overall, these results support the hypothesis that genetic factors control subphenotypes, according to gender and age, and that failure to address that complexity will hamper to unravel the etiology of asthma and related phenotypes. At the clinical and biological level, phenotypic heterogeneity may be explained by gene-environment interactions according to windows of exposure38-40. In any case, these results demonstrate that careful characterization of subphenotypes in allergy and asthma may improve our understanding of the etiology of asthma, and ultimately assist in the management of this complex disease.

\title{
Ackowledgements:
}

Supported by Cohorts and collections (Inserm/Ministry of Research), AFSSET, ANR-PSET, and Agir adom

\section{Footnotes:}

\section{EGEA COOPERATIVE GROUP}

Coordination: F Kauffmann; F Demenais (genetics); I Pin (clinical aspects).

Respiratory epidemiology: Inserm U 578, Grenoble: V Siroux; Inserm U 700, Paris M Korobaeff (EGEA1), F Neukirch (EGEA1); Inserm U 707, Paris: I Annesi-Maesano; Inserm U 780, Villejuif: F Kauffmann, N Le Moual, R Nadif, MP Oryszczyn.

Genetics: Inserm U 393, Paris: J Feingold; Inserm U 535, Villejuif: MH Dizier; Inserm U 794, Evry: E Bouzigon, F Demenais; CNG, Evry: I Gut, M Lathrop.

Clinical centers: Grenoble: I Pin, C Pison; Lyon: D Ecochard (EGEA1), F Gormand, Y Pacheco; Marseille: D Charpin (EGEA1), D Vervloet; Montpellier: J Bousquet; Paris Cochin: A Lockhart (EGEA1), R Matran (now in Lille); Paris Necker: E Paty, P Scheinmann; Paris-Trousseau: A Grimfeld, J Just.

Data and quality management: Inserm ex-U155 (EGEA1): J Hochez; Inserm U 780, Villejuif: N Le Moual, C Ravault; Inserm U 794: N Chateigner; Grenoble: J Ferran

\author{
ABBREVIATIONS \\ CI: Confidence interval \\ EGEA: Epidemiological study on the Genetics and Environment of Asthma, bronchial hyperresponsiveness and atopy \\ $\mathrm{FEV}_{1}$ : forced expiratory volume in one second \\ GM: Geometric mean \\ IgE: Immunoglobulin E \\ IU: International unit \\ SPT: Skin prick test \\ SPT+: Skin prick test positivy
}


SPTQ: Skin prick test quantitative score

\section{References:}

- 1. Van Dellen RG The eosinophil: friend or foe?. Mayo Clin Proc. 1981; 56: 395- 6

- 2. Busse WW The eosinophil--quo vadis?. J Allergy Clin Immunol. 2004; 113: 38- 42

- 3. Miranda C, Busacker A, Balzar S , Trudeau J , Wenzel SE Distinguishing severe asthma phenotypes: role of age at onset and eosinophilic inflammation. J Allergy Clin Immunol. 2004; 113: 101- 8

- 4. Postma DS , Boezen HM Rationale for the Dutch hypothesis. Allergy and airway hyperresponsiveness as genetic factors and their interaction with environment in the development of asthma and COPD. Chest. 2004; 126: (2 Suppl) 96S- 104S

- 5. Gottlieb DJ , Sparrow D, O'Connor GT , Weiss ST Skin test reactivity to common aeroallergens and decline of lung function. The Normative Aging Study. Am J Respir Crit Care Med. 1996; 153: 561- 6

- 6. Frette C, Annesi I, Korobaeff M, Neukirch F, Dore MF, Kauffmann F Blood eosinophilia and FEV1. Cross-sectional and longitudinal analyses. Am Rev Respir Dis. 1991; 143: (5 Pt 1) 987- 92

- 7. Lapperre TS , Snoeck-Stroband JB , Gosman MM, Stolk J, Sont JK, Jansen DF Dissociation of lung function and airway inflammation in chronic obstructive pulmonary disease. Am J Respir Crit Care Med. 2004; 170: 499- 504

- 8. Jansen DF, Rijcken B , Schouten JP, Kraan J , Weiss ST, Timens W, Postma DS The relationship of skin test positivity, high serum total IgE levels, and peripheral blood eosinophilia to symptomatic and asymptomatic airway hyperresponsiveness. Am J Respir Crit Care Med. 1999; 159: 924- 31

- 9. Baldacci S , Omenaas E , Oryszczyn MP Allergy markers in respiratory epidemiology. Eur Respir J. 2001; 17: 773- 90

- 10. Douwes J , Gibson P, Pekkanen J , Pearce N Non eosinophilic asthma: importance and possible mechanisms. Thorax. 2002; 57: 643- 8

- 11. Siroux V , Curt F, Oryszczyn MP, Maccario J, Kauffmann F Role of gender and hormone-related events on IgE, atopy and eosinophils in the Epidemiological study on the Genetics and Environment of Asthma, bronchial hyperresponsiveness and atopy. J Allergy Clin Immunol. 2004; 114: 491- 98

- 12. Bouzigon E, Chaudru V , Carpentier AS , Dizier MH, Oryszczyn MP, Maccario J Familial correlations and inter-relationships of four asthma-associated quantitative phenotypes in 320 French EGEA families ascertained through asthmatic probands. Eur J Hum Genet. 2004; 12: 955- 63

- 13. Oryszczyn MP, Annesi-Maesano I, Charpin D, Paty E, Maccario J , Kauffmann F Relationships of active and passive smoking to total IgE in adults of the Epidemiological study of the Genetics and Environment of Asthma, bronchial hyperresponsiveness, and atopy (EGEA). Am J Respir Crit Care Med. 2000; 161: 1241- 6

- 14. Matricardi PM , Rosmini F, Riondino S, Fortini M, Ferrigno L, Rapicetta M, Bonini S Exposure to foodborne and orofecal microbes versus airborne viruses in relation to atopy and allergic asthma: epidemiological study. BMJ. 2000; 320: 412- 7

- 15. Kauffmann F , Oryszczyn MP , Maccario J The protective role of country living on skin prick tests, immunoglobulin E and asthma in adults from the Epidemiological study on the Genetics and Environment of Asthma, bronchial hyper-responsivenes and atopy. Clin Exp Allergy. 2002; 32: 379- 86

- 16. Maccario J , Oryszczyn MP , Charpin D , Kauffmann F Methodologic aspects of the quantification of skin prick test responses: the EGEA study. J Allergy Clin Immunol. 2003; 111: 750- 6

- 17. Kauffmann F, Dizier MH , Pin I, Paty E , Gormand F, Vervloet D Epidemiological study on the genetics and environment of asthma, bronchial hyperresponsiveness and atopy (EGEA) - Phenotype issues. Am J Respir Crit Care Med. 1997; 156: S123- S129

- 18. Kauffmann F, Dizier MH, Annesi-Maesano I, Bousquet J , Charpin D, Demenais F Epidemiological study of genetic and environmental factors in asthma, bronchial hyperresponsiveness and atopy. Protocol and potential selection bias. Rev Epidémiol Santé Publ. 2001; 49: 343- 56

- 19. Le Moual N, Siroux V, Pin I , Kauffmann F , Kennedy S on behalf of the Epidemiological Study on the genetics and Environment of Asthma (EGEA) Asthma severity and exposure to occupational asthmagens. Am J Respir Crit Care Med. 2005; 172: 440- 5

- 20. Oryszczyn MP, Annesi-Maesano I, Charpin D , Kauffmann F Allergy markers in adults in relation to the timing of pet exposure in the EGEA study. Allergy. 2003; 58: 1136- 43

- 21. Oryszczyn MP, Van Ree R, Maccario J , Kauffmann F Relationships between current and past exposure to cat and specific IgE, IgG4 and atopy in 364 adults of the EGEA study. Proc Am Thorac Soc. 2006;

- 22. Varraso R, Siroux V , Maccario J , Pin I, Kauffmann F on behalf of the Epidemiological Study on the genetics and Environment of Asthma (EGEA) Asthma severity is associated with body mass index and early menarche in women. Am J Respir Crit Care Med. 2005; 171: 334- 9

- 23. Becklake MR , Kauffmann F Gender differences in airway behaviours over the human life span. Thorax. 1999; 54: 1119- 38

- 24. Wright AL, Stern DA, Kauffmann F, Martinez FD Factors influencing gender differences in the diagnosis and treatment of asthma in childhood: The Tucson Children's Respiratory Study. Ped Pulmonology. 2006; 41: 318- 25

- 25. Barbee RA, Halonen M , Lebowitz M , Burrows B Distribution of IgE in a community population sample: correlations with age, sex, and allergen skin test reactivity. J Allergy Clin Immunol. 1981; 68: 106- 11

- 26. Siroux V, Oryszczyn MP, Paty E, Kauffmann F, Pison C, Vervloet D, Pin I Relationships of allergic sensitisation, total IgE and blood eosinophils to asthma severity in children of the EGEA Study. Clin Experim Allergy. 2003; 33: 746- 51

- 27. Heaton T, Rowe J , Turner S, Aalberse RC, de Klerk N, Suriyaarachchi D An immunoepidemiological approach to asthma: identification of in-vitro T-cell response patterns associated with different wheezing phenotypes in children. Lancet. 2005; 365: 142- 9

- 28. Lewis SA, Pavord ID , Stringer JR , Knox AJ , Weiss ST , Britton JR The relation between peripheral blood leukocyte counts and respiratory symptoms, atopy, lung function, and airway responsiveness in adults. Chest. 2001; 119: 105- 14

- 29. Williams TJ The eosinophil enigma. J Clin Invest. 2004; 113: 507- 9

- 30. Wills-Karp M , Karp CL Eosinophils in asthma: Remodeling a tangled tale. Science. 2004; 305: 1726- 29

- 31. Giembycz MA , Lindsay MA Pharmacology of the eosinophil. Pharmacol Rev. 1999; 51: 213- 340

- 32. Pascual RM , Peters SP Airway remodeling contributes to the progresive loss of lung function in asthma: an overview. J Allergy Clin Immunol. 2005; 116 : 477- 86

- 33. Strunk RC, Szefler SJ , Phillips BR, Zeiger RS , Chinchilli VM , Larsen G Relationship of exhaled nitric oxide to clinical and inflammatory markers of persistent asthma in children. J Allergy Clin Immunol. 2003; 112: 883- 92

- 34. Siroux V , Kauffmann F , Pison C, Pin I Multidimensional character of asthma severity in the EGEA study. Rev Mal Respir. 2004; 21 : (5 Pt 1) 917- 24

- 35. Arshad SH Primary prevention of asthma and allergy. J Allergy Clin Immunol. 2005; 116: 3- 14

- 36. Frew AJ Advances in environmental and occupational diseases 2004. J Allergy Clin Immunol. 2005; 115: 1197- 202

- 37. von Mutius E Influences in allergy: epidemiology and the environment. J Allergy Clin Immunol. 2004; 113: 373- 9

- 38. Hoffjan S, Nicolae D, Ostrovnaya I, Roberg K, Evans M , Mirel DB Gene-environment interaction effects on the development of immune responses in the 1st year of life. Am J Hum Genet. 2005; 76: 696- 704

- 39. Martinez FD Gene-environment interactions in asthma and allergies: a new paradigm to understand disease causation. Immunol Allergy Clin North Am. 2005; 25: 709- 21

- 40. Ober C , Thompson EE Rethinking genetic models of asthma: the role of environmental modifiers. Curr Opin Immunol. 2005; 17: 670- 8 
Figure 1

Concordance of SPT+, high IgE and eosinophilia in asthmatic cases according to age and gender (Venn diagrams)
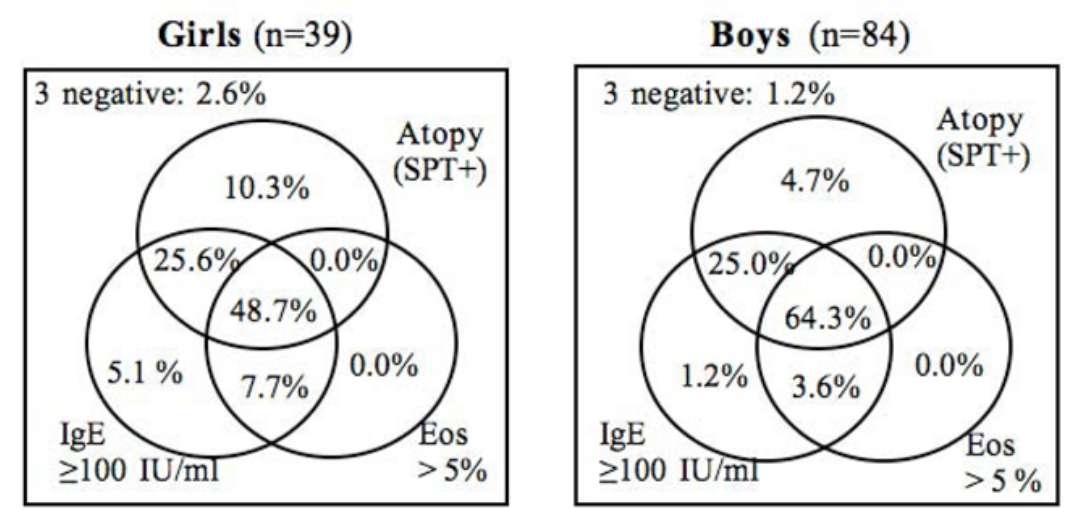

Women $(\mathrm{n}=87)$
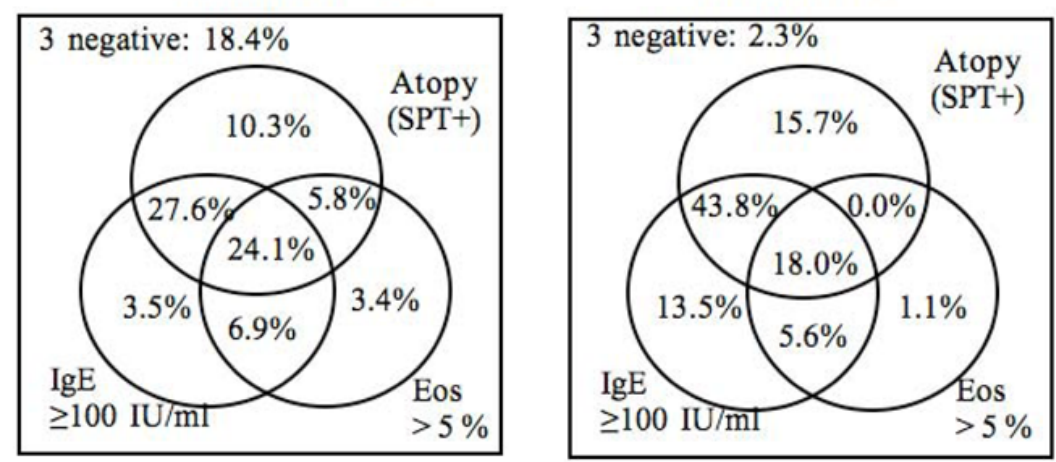

\section{Figure 2}

Associations of total IgE, eosinophil count and $\mathrm{FEV}_{1} / \mathrm{Height}^{2}$ by age in cases and controls over the life span

Controls $(n=309)$ and cases $(n=299)$ are represented by open circles/thin curve by closed circles/thick curve, respectively. Cases and controls differed significantly for all parameters $(\mathrm{p}<0.001)$. $\mathrm{FEV}^{1} / \mathrm{Height}^{2}$ decline, with age among adults was significantly steeper in cases than in controls $(\mathrm{p}<0.001)$,

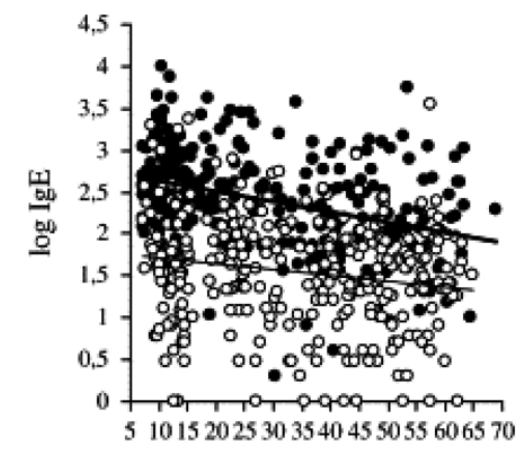

Age

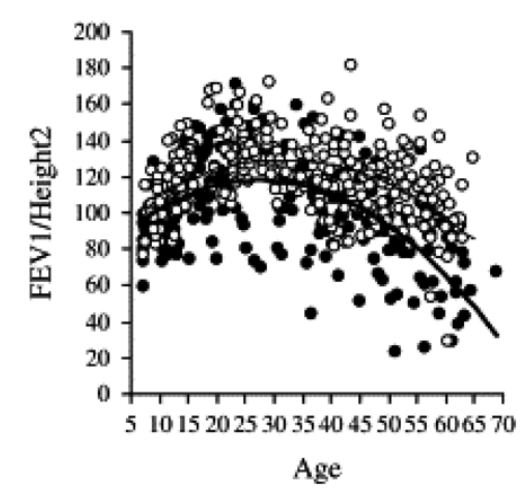

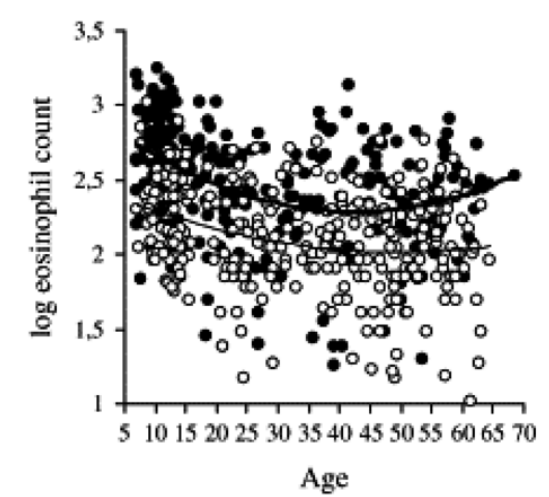

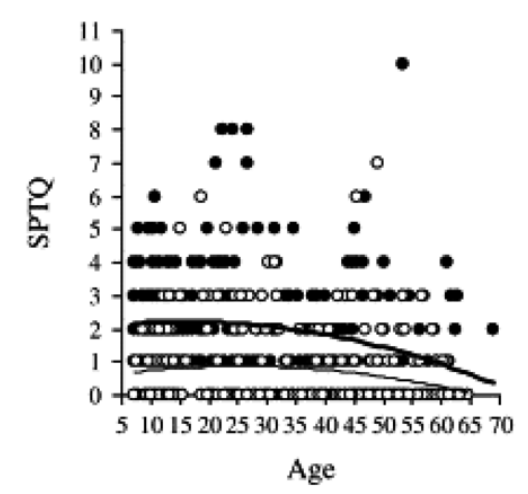


Figure 3

Associations of total IgE, SPTQ and $\mathrm{FEV}_{1}$ with eosinophil tertiles according to asthma in children and adults

SPTQ: Number of positive skin prick tests Numbers of subjects in each group are shown below each bar * $\mathrm{p} \leq 0.01 \mathrm{\ddagger p} \leq 0.05$

Children
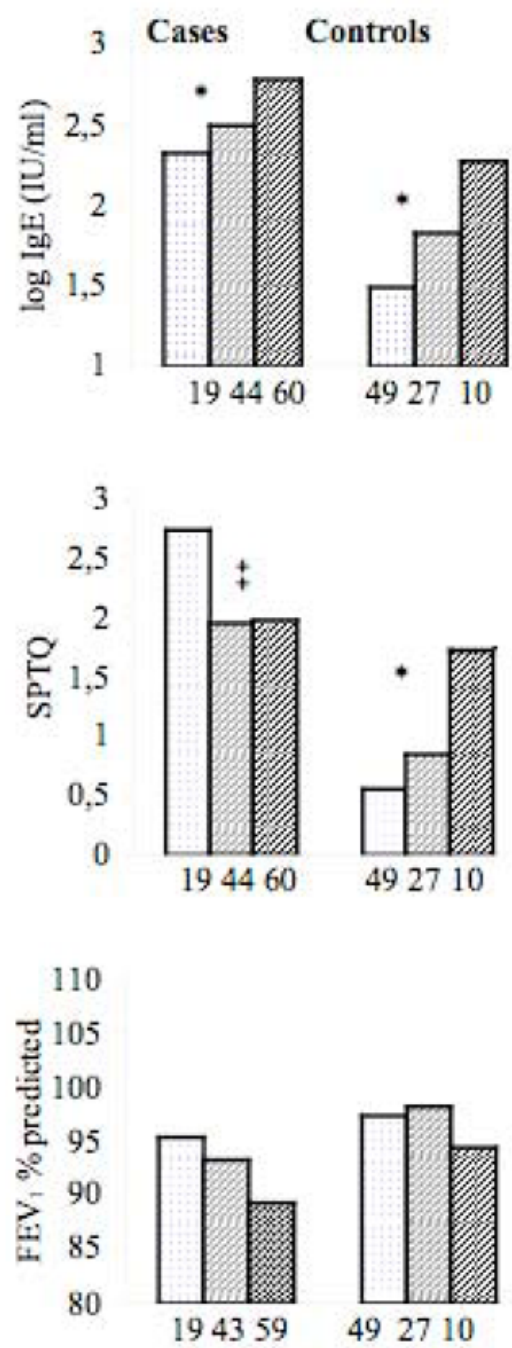

\section{Adults}
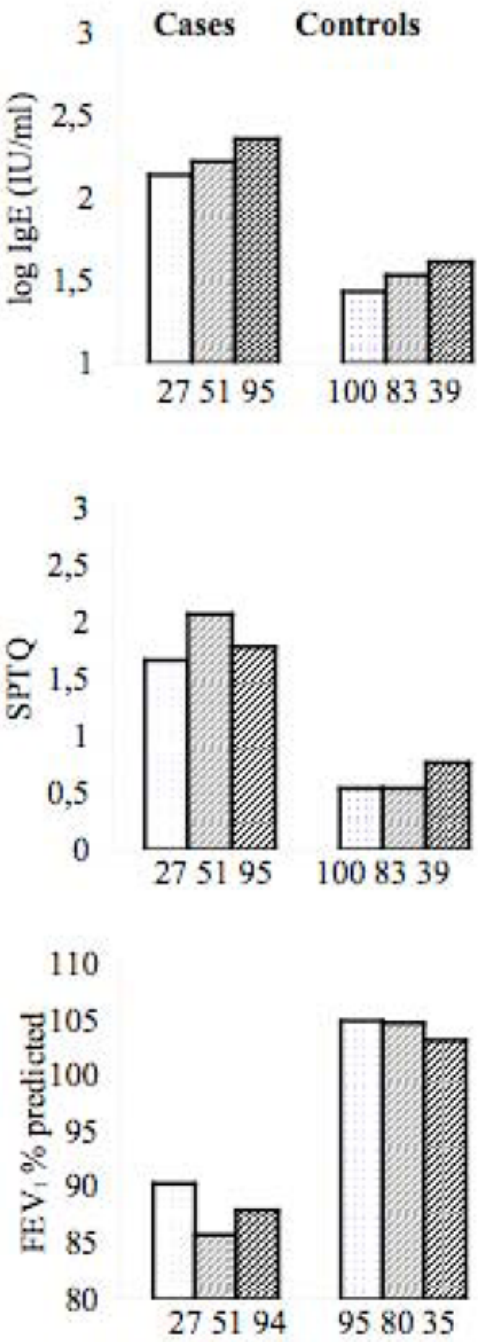

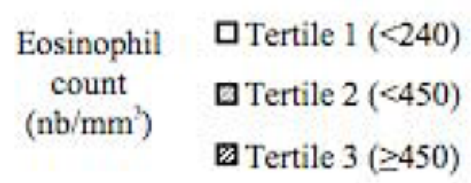

$\begin{array}{cc}\begin{array}{c}\text { Eosinophil } \\ \text { count } \\ \left(\mathrm{nb} / \mathrm{mm}^{3}\right)\end{array} & \text { aTertile } 1(<110) \\ & \text { aTertile 2 }(<240) \\ & \text { QTertile } 3(\geq 240)\end{array}$ 
Table I

Characteristics of the population

\begin{tabular}{|c|c|c|c|c|c|c|c|c|}
\hline & \multicolumn{4}{|c|}{ Females } & \multicolumn{4}{|c|}{ Males } \\
\hline & \multicolumn{2}{|c|}{ Children } & \multicolumn{2}{|c|}{ Adults } & \multicolumn{2}{|c|}{ Children } & \multicolumn{2}{|c|}{ Adults } \\
\hline & Cases $(n=39)$ & Controls $(n=45)$ & Cases $(n=87)$ & Controls $(n=111)$ & Cases $(n=84)$ & Controls $(n=41)$ & Cases $(n=89)$ & Controls $(n=112)$ \\
\hline Age, $\mathrm{m} \pm \mathrm{SD}$, years & $11.1 \pm 2.0$ & $12.1 \pm 2.2^{*}$ & $35.4 \pm 13.3$ & $40.0 \pm 12.0^{*}$ & $11.3 \pm 2.1$ & $12.2 \pm 2.3^{*}$ & $40.1 \pm 15.0$ & $43.6 \pm 13.2^{\dagger}$ \\
\hline Total IgE, IU/ml, GM [95\% CI] & $312[36-2688]$ & $36[1-937]^{\ddagger}$ & 161 [7-3874] & $28[1-542]^{\ddagger}$ & 454 [49-4198] & $68[4-1551]^{\ddagger}$ & $228[20-2620]$ & $36[2-647]^{\ddagger}$ \\
\hline $\mathrm{IgE} \geq 100 \mathrm{IU} / \mathrm{ml}, \%$ & 87.2 & $24.4^{\ddagger}$ & 62.1 & $19.8^{\ddagger}$ & 94.0 & $34.1^{\ddagger}$ & 80.9 & $20.5^{\ddagger}$ \\
\hline Specific IgE, Phadiatop ${ }^{\circledR+}, \%$ & 94.9 & $22.2^{\ddagger}$ & 66.7 & $19.8^{\ddagger}$ & 92.9 & $36.6^{\ddagger}$ & 78.7 & $22.3^{\ddagger}$ \\
\hline SPT+, any, $\%$ & 84.6 & $42.2^{\ddagger}$ & 67.8 & $27.0^{\ddagger}$ & 94.0 & $46.3^{\ddagger}$ & 77.5 & $34.8^{\ddagger}$ \\
\hline $\mathrm{SPT}+$, indoor, \% & 79.5 & $24.4^{\ddagger}$ & 60.9 & $21.6^{\ddagger}$ & 88.1 & $24.4^{\ddagger}$ & 61.8 & $20.5^{\ddagger}$ \\
\hline SPT+, outdoor, $\%$ & 51.3 & $18.2^{\S}$ & 36.8 & 17.1 & 42.9 & $26.8^{\dagger}$ & 46.1 & $18.8^{\ddagger}$ \\
\hline SPT + , moulds, $\%$ & 18.4 & 22.2 & 20.7 & $7.2^{\S}$ & 23.8 & 17.5 & 24.7 & $10.7^{\S}$ \\
\hline $\mathrm{SPTQ}, \mathrm{m} \pm \mathrm{SD}$ & $1.9 \pm 1.2$ & $0.7 \pm 0.9^{\ddagger}$ & $1.7 \pm 1.8$ & $0.6 \pm 1.3^{\ddagger}$ & $2.2 \pm 1.3$ & $0.9 \pm 1.2^{\ddagger}$ & $2.0 \pm 1.9$ & $0.7 \pm 1.1^{\ddagger}$ \\
\hline Eosinophils nb/mm³ ${ }^{3}$ GM [95\% CI] & $376[94-1509]$ & $168[48-588]^{\ddagger}$ & $260[50-1342]$ & $102[19-557]^{\ddagger}$ & $474[136-1652]$ & $212[56-804]^{\ddagger}$ & $207[39-1096]$ & $124[32-475]^{\ddagger}$ \\
\hline $\mathrm{FEV}_{1} \%$ pred, $\mathrm{m} \pm \mathrm{SD}$ & $90.5 \pm 9.8$ & $95.4 \pm 12.1^{*}$ & $89.9 \pm 19.9$ & $105.0 \pm 13.1^{\ddagger}$ & $92.1 \pm 13.1$ & $99.2 \pm 10.4^{\ddagger}$ & $85.5 \pm 21.9$ & $103.7 \pm 15.0^{\ddagger}$ \\
\hline $\mathrm{FEV}_{1} \%$ pred $<80 \%, \%$ & 15.4 & 8.9 & 27.6 & $0.9^{\ddagger}$ & 16.7 & $2.4^{*}$ & 36.0 & $3.6^{\ddagger}$ \\
\hline $\begin{array}{l}\text { Comparison of cases and controls } \\
{ }_{*} \mathrm{p} \leq 0.05 \\
\oint_{\mathrm{p}} \leq 0.10 \\
\ddagger_{\mathrm{p}} \leq 0.01 \\
{ }_{\mathrm{p}} \leq 0.001\end{array}$ & & & & & & & & \\
\hline
\end{tabular}

